\title{
Vibration Characteristic Analysis of Vehicle Air Suspension Based on Fuzzy Control
}

\author{
CHEN Ke ${ }^{1, a}$, ZHANG Ming ${ }^{1, b}$ and TONG Xuefeng ${ }^{1, c}$ \\ ${ }^{1}$ School of Automotive and Traffic, Shenyang Ligong University, Shenyang 110159, China \\ achen_ke@163.com, 'bm326419645@yahoo.cn, 'tongtong0618@126.com
}

Keywords: air suspension; ride comfort; fuzzy control; MATLAB/Simulink

\begin{abstract}
The air suspension has the characteristics of nonlinear variable spring rate. To improve vehicle handling stability and ride comfort, the characteristic curve can be designed to comply with the vehicle vibration. In this paper, air suspension and whole vehicle were selected as research object; vehicle's mathematical model was established based on vehicle dynamic theory, the state space expression and suspension system frequency response function of mathematical model were derived. Fuzzy control was adopted as air suspension control strategy; vehicle's ride comfort was analyzed and simulated using MATLAB/Simulink. The body vertical acceleration, the body pitch angular acceleration and the suspension deflections are obtained. Simulation results show that the mathematical model is reasonable. The fuzzy controller has a good performance to meet the actual demand. Vehicle's ride comfort is improved.
\end{abstract}

\section{Introduction}

Suspension is an important assembly; it joins elastic frames and axles. The suspension system can markedly reduce the vibration and shock caused by uneven road, expeditiously attenuate vibration of the body and axle, transfer the forces and moments between the wheels and the automobile's frame. To ensure that the car ride comfort and handling stability, driving safety.With the development of society and the continuous improvement of people's living standards, the automobile riding comfort has to meet more strict demands. The passive suspension system has been difficult to meet the more strict demands for the ride comfort and handling stability, so the better performance of the air suspension is one of the solutions. The air suspension can effectively resist the body vertical vibration caused by the uneven road[1,2], and therefore can greatly improve the ride comfort of the vehicle in the uneven road. For example, when turning, the air suspension can automatically provide the functions of the body anti-roll[3,4].

In this paper, according to the kinetic theory, establishing vehicle vibration model of 7 degrees by analysis of vehicle systems and simplified, derivation of spatial expression of the mathematical model of the vehicle. In MATLAB fuzzy control system, to determine the input and output linguistic variables and membership of function type, fuzzification, defuzzification method and fuzzy control rules. Ride comfort simulation of the mathematical model using fuzzy controller.

\section{Establishment of Mathematical Model of Whole Vehicle}

The whole vehicle 7-DOF dynamic model was shown in Figure1, set $o$ to body mass, travelling along a straight line.

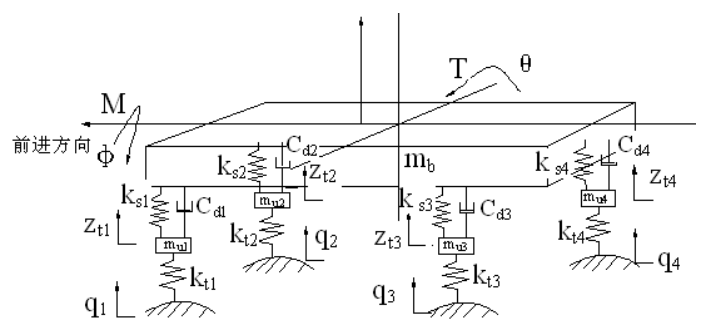

Fig.1 whole vehicle simplified mechanical model

Make the following assumptions[5]: (1) A vehicle system is nonlinear systems, suspension 
system with nonlinear stiffness and linear damping coefficient; (2) Sprung mass and unsprung weight is rigid, and perpendicular to the vertical surface; (3) Sum of the front axle and front wheel quality is front unsprung mass, Quality of rear wheels and rear axle is rear unsprung mass. Under the assumption of above, vehicle vibration differential equation expressed in the following matrix form:

$[M][\ddot{x}]+[c][\dot{x}]+[k][x]=[F]=\left[k_{q}\right][Q]$

In equation (1), the physical meaning of symbols is: $[x]=\left[z, \theta, \varphi, z_{\mathrm{t} 1}, z_{\mathrm{t} 2}, z_{\mathrm{t} 3}, z_{\mathrm{t} 4}\right]^{\mathrm{T}},[Q]=\left[q_{1}, q_{2}, q_{3}, q_{4}\right]^{\mathrm{T}}$; in which, $z, \theta, \varphi, z_{\mathrm{t} 1}, \mathrm{z}_{\mathrm{t} 2}, z_{\mathrm{t} 3}, z_{\mathrm{t} 4}$ is vertical displacement, pitch angle, roll angle and vertical displacement of four wheels, respectively; $q_{1}, q_{2}, q_{3}, q_{4}$ is road roughness of four wheels respectively. $[M]$ is mass matrix; $[C]$ is the damping matrix; $[k]$ is stiffness matrix.

The vibration differential equations of 7 freedoms for the whole vehicle are built based on Newton's second law. The equations are as follows.

$$
\begin{aligned}
& \left(m_{b} \ddot{z}+\left(C_{d 1}+C_{d 2}+C_{d 3}+C_{d 4}\right) \dot{\mathrm{z}}+\left(-L_{1} C_{d 1}-L_{1} C_{d 2}-L_{2} C_{d 3}-L_{2} C_{d 4}\right) \dot{\theta}+\left(b_{1} C_{d 1}-b_{1} C_{d 2}+b_{2} C_{d 3}-b_{2} C_{d 4}\right) \dot{\varphi}\right. \\
& \dot{z}_{t 1} C_{d 1}-\dot{z}_{t 2} C_{d 2}-\dot{z}_{t 3} C_{d 3}-\dot{z}_{t 4} C_{d 4}+\left(k_{s 1}+k_{s 2}+k_{s 3}+k_{s 4}\right) \mathrm{z}+\left(-L_{1} k_{s 1}-L_{1} k_{s 2}-L_{2} k_{s 3}-L_{2} k_{s 4}\right) \theta+ \\
& \left(b_{1} k_{s 1}-b_{1} k_{s 2}+b_{2} k_{s 3}-b_{2} k_{s 4}\right) \varphi-z_{t 1} k_{s 1}-z_{t 2} k_{s 2}-z_{t 3} k_{s 3}-z_{t 4} k_{s 4}=0 \\
& I_{y} \ddot{\theta}+\left(-L_{1} C_{d 1}-L_{1} C_{d 2}+L_{2} C_{d 3}+L_{2} C_{d 4}\right) \dot{z}+\left(L_{1}^{2} C_{d 1}+L_{1}^{2} C_{d 2}+L_{2}^{2} C_{d 3}+L_{2}^{2} C_{d 4}\right) \dot{\theta}+\left(-b_{1} L_{1} C_{d 1}+b_{1} L_{1} C_{d 2}+b_{2} L_{2} C_{d 3^{-}}\right. \\
& \left.b_{2} L_{2} C_{d 4}\right) \dot{\varphi}+z_{t 1} L_{1} C_{d 1}+\dot{z}_{t 2} L_{1} C_{d 2}-\dot{z}_{t 3} L_{2} C_{d 3}-\dot{z}_{t 4} L_{2} C_{d 4}+\left(-L_{1} k_{s 1}-L_{1} k_{s 2}+L_{2} k_{s 3}+L_{2} k_{s 4}\right) z+\left(L_{1}^{2} k_{s 1}+L_{1}^{2} k_{s 2}+\right. \\
& \left.L_{2}^{2} k_{s 3}+L_{2}^{2} k_{s 4}\right) \theta+\left(-b_{1} L_{1} k_{s 1}+b_{1} L_{1} k_{s 2}+b_{2} L_{2} k_{s 3}-b_{2} L_{2} k_{s 4}\right) \varphi+z_{t 1} L_{1} k_{s 1}+z_{t 2} L_{1} k_{s 2}-z_{t 3} L_{2} k_{s 3}-z_{t 4} L_{2} k_{s 4}=0 \\
& \left\{I_{x} \ddot{\theta}+\left(b_{1} C_{d 1}-b_{1} C_{d 2}+b_{2} C_{d 3}-b_{2} C_{d 4}\right) \dot{z}+\left(-L_{1} b_{1} C_{d 1}+L_{1} b_{1} C_{d 2}+L_{2} b_{2} C_{d 3}-L_{2} b_{2} C_{d 4}\right) \dot{\theta}+\left(b_{1}^{2} C_{d 1}+b_{1}^{2} C_{d 2}+b_{2}^{2} C_{d 3}+\right.\right. \\
& \left.b_{2}^{2} C_{d 4}\right) \dot{\varphi} \dot{z}_{t 1} b_{1} C_{d 1}+\dot{z}_{t 2} b_{1} C_{d 2} \dot{z}_{t 3} b_{2} C_{d 3}+\dot{z}_{t 4} b_{2} C_{d 4}+\left(b_{1} k_{s 1}-b_{1} k_{s 2}+b_{2} k_{s 3}-b_{2} k_{s 4}\right) z+\left(-b_{1} L_{1} k_{s 1}+b_{1} L_{1} k_{s 2}+\right. \\
& \left.b_{2} L_{2} k_{s 3}-b_{2} L_{2} k_{s 4}\right) \theta+\left(b_{1}^{2} k_{s 1}+b_{1}^{2} k_{s 2}+b_{2}^{2} k_{s 3}+b_{2}^{2} k_{s 4}\right) \varphi-z_{t 1} b_{1} k_{s 1}+z_{t 2} b_{1} k_{s 2}-z_{t 3} b_{2} k_{s 3}+z_{t 4} b_{2} k_{s 4}=0 \\
& m_{u 1} \ddot{z}_{t 1}-C_{d 1} \dot{z}+L_{1} C_{d 1} \dot{\theta}-b_{1} C_{d 1} \dot{\varphi}+\dot{z}_{t 1} C_{d 1}-k_{s 1} z+L_{1} k_{s 1} \theta-b_{1} k_{s 1} \varphi+z_{t 1}\left(k_{s 1}+k_{t 1}\right)=k_{t 1} q_{1} \\
& m_{u 2} \ddot{z}_{t 2}-C_{d 2} \dot{z}+L_{1} C_{d 2} \dot{\theta}-b_{1} C_{d 2} \dot{\varphi}+\dot{z}_{t 2} C_{d 2}-k_{s 2} z+L_{1} k_{s 2} \theta-b_{1} k_{s 2} \varphi+z_{t 2}\left(k_{s 2}+k_{t 2}\right)=k_{t 2} q_{2} \\
& m_{u 3} \ddot{z}_{t 3}-C_{d 3} \dot{z}+L_{2} C_{d 3} \dot{\theta}-b_{2} C_{d 3} \dot{\varphi}+\dot{z}_{t 3} C_{d 3}-k_{s 3} z+L_{2} k_{s 3} \theta-b_{2} k_{s 3} \varphi+z_{t 3}\left(k_{s 3}+k_{t 3}\right)=k_{t 3} q_{3} \\
& m_{u 4} \ddot{z}_{t 4}-C_{d 4} \dot{z}+L_{2} C_{d 4} \dot{\theta}-b_{2} C_{d 4} \dot{\varphi}+\dot{z}_{t 4} C_{d 4}-k_{s 4} z+L_{2} k_{s 4} \theta-b_{2} k_{s 4} \varphi+z_{t 4}\left(k_{s 4}+k_{t 4}\right)=k_{t 4} q_{4}
\end{aligned}
$$

Where: $[x]=\left[z, \theta, \varphi, z_{t 1}, z_{t 2}, z_{t 3}, z_{t 4}\right]^{\mathrm{T}}=\left[x_{1}, x_{2}, x_{3}, x_{4}, x_{5}, x_{6}, x_{7}\right]^{\mathrm{T}}$ is state variable; $[u]=\left[q_{1}, q_{2}, q_{3}, q_{4}\right]^{\mathrm{T}}$ is input variable; $[Y]=\left[\ddot{z}, \ddot{\theta}, \ddot{\varphi}, z-L_{1} \theta+b_{1} \varphi-z_{t 1}, z-L_{1} \theta+b_{1} \varphi-z_{t 2}, z-L_{1} \theta+b_{1} \varphi-z_{t 3}, z-L_{1} \theta+b_{1} \varphi-z_{t 4}, z_{t 1}-q_{1}, z_{t 2}-q_{2}\right.$,

$\left.z_{t 3}-q_{3}, z_{t 4}-q_{4}\right]$ is output variable, in which: $\ddot{z}$ is the vehicle vertical acceleration, $\ddot{\theta}$ is the vehicle pitch acceleration, $\ddot{\varphi}$ is the vehicle lateral acceleration, $z-L_{1} \theta+b_{1} \varphi-z_{t 1}$ c is left front suspension deflections, $z-L_{1} \theta+b_{1} \varphi-z_{t 2}$ is right front suspension deflections, $z-L_{1} \theta+b_{1} \varphi-z_{t 3}$ is left rear suspension deflections, $z-L_{1} \theta+b_{1} \varphi-z_{t 4}$ is right rear suspension deflections, $z_{t 1}-q_{1}$ is left front tire dynamic load, $z_{t 2}-q_{2}$ is right front tire dynamic load, $z_{t 3}-q_{3}$ is left rear tire dynamic load, $z_{t 4}-q_{4}$ is right rear tire dynamic load.

\section{Statistical Characteristics of Road Surface Roughness}

$x(I), y(I)$ is wheel track roughness of the left and right wheels, $I$ is road-length. The spectra and cross-spectra of $x(I)$ and $y(I)$ is $G_{x x}(n), G_{y y}(n), G_{x y}(n)$ and $G_{y x}(n)$ respectively. Roughness functions of four wheels are defined as $q_{1}(I), q_{2}(I), q_{3}(I)$ and $q_{4}(I)$. The roughness functions of two front wheels are $q_{1}(I)=x(I), q_{3}(I)=y(I)$. Because the rear wheels lags behind front wheels, lag distance to $L, L$ is the automobile wheelbase. So, the roughness functions of two rear wheels are $q_{2}(I)=x(I-L)$, $q_{4}(I)=y(I-L)$.

Cross-spectral density is plural, left and right wheel track of cross spectrum can be represented as:

$G_{x y}(n)=\left|G_{x y}(n)\right| e^{-j \phi_{x y}(n)}$ 
In which, $\left|G_{x y}(n)\right|$ is cross-amplitude spectra of $x(I)$ and $y(I) ; \phi_{x y}(n)$ is phase spectrum of $x(I)$ and $y(I)$.

The input power spectral density matrix for four-wheeled vehicles is:

$$
\left[G_{q}(n)\right]=\left[\begin{array}{llll}
1 & \operatorname{coh}(n) & e^{-j 2 \pi n L} & \operatorname{coh}(n) e^{-j 2 \pi n L} \\
\operatorname{coh}(n) & 1 & \operatorname{coh}(n) e^{-j 2 \pi n L} & e^{-j 2 \pi n L} \\
e^{j 2 \pi n L} & \operatorname{coh}(n) e^{j 2 \pi n L} & 1 & \operatorname{coh}(n) \\
\operatorname{coh}(n) e^{j 2 \pi n L} & e^{j 2 \pi n L} & \operatorname{coh}(n) & 1
\end{array}\right] \cdot G_{q}(n)
$$

$\operatorname{coh}_{x y}(n)$ is coefficient of coherence of two wheels, it can be solved approximate by the curve fitting.

\section{Establishment of Fuzzy Control System}

Automotive suspension system is a complex non-linear system; using conventional linear system control theory is difficult to achieve good control effect. Because there is no need to establish precise mathematical model of the control system using fuzzy control strategy, can avoid effects of system modeling errors, which can get better control effect. Fuzzy control system of air suspension is established using the MATLAB fuzzy module. As shown in Figure 2.

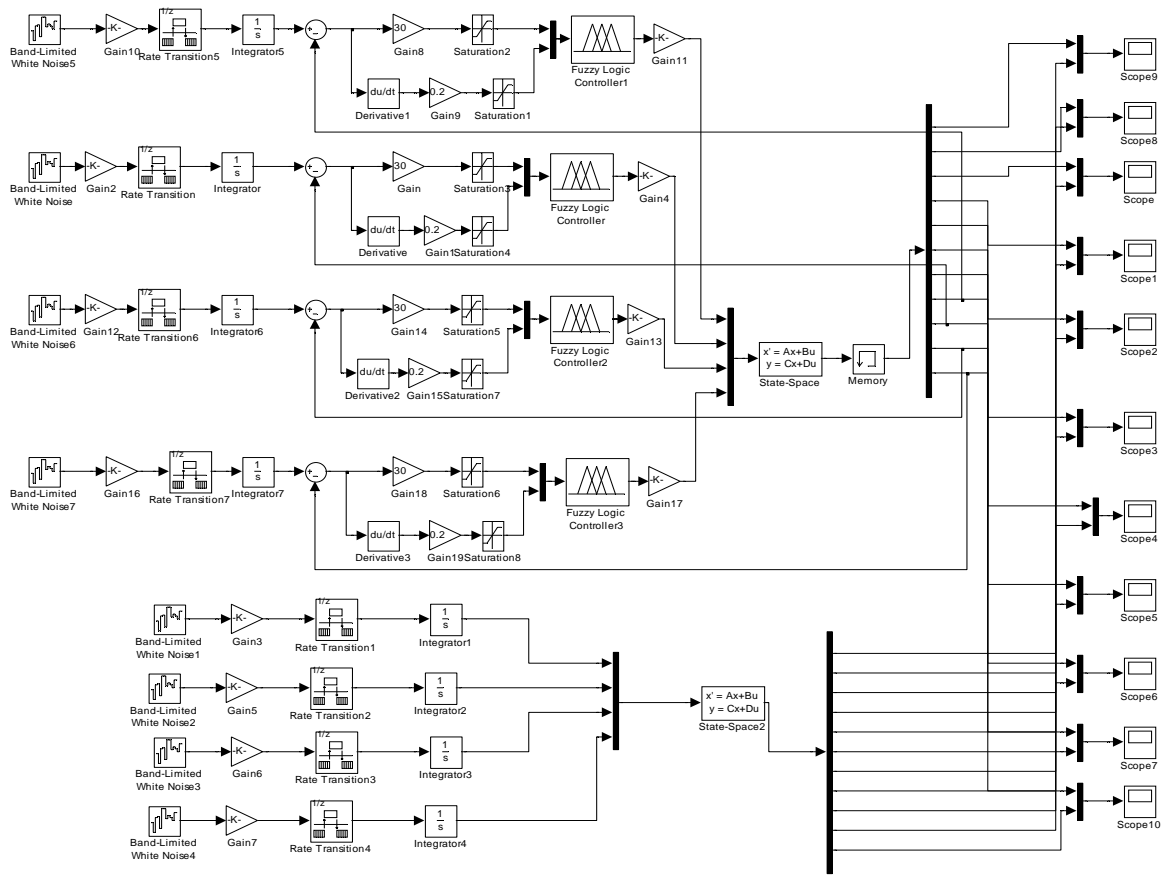

Fig.2 The simulink simulation diagram of vehicle dynamics

\section{Time Domain Analysis of Ride Comfort of Whole Vehicle Dynamics}

Figure 3 to figure 8 are contrast curve of the air suspension and passive suspension at $60 \mathrm{Km} / \mathrm{h}$ in b-level roads, include body vertical acceleration, body pitch angular acceleration, the left front suspension deflections, the front right suspension deflections, the left rear suspension deflections, right suspension dynamic deflection.

From Figure 3 to figure 8, comparison of passive suspension and air suspension with fuzzy control on the body acceleration, the body vertical acceleration and pitch angular acceleration with air suspension are apparent attenuation, dramatically improves the ride comfort of vehicles. In terms of dynamic deflection of suspensions, suspensions dynamic deflection with air suspension using fuzzy control than dynamic deflection of passive suspensions significantly reduced, attenuate to 25\%-50\%. Therefore, without destroying the ride comfort, reduces the probability of impacting suspension limit, enhances ride comfort, and to some extent also improves vehicle handling and 
stability. In short, air suspension with fuzzy control improves ride comfort and safety of the vehicle.

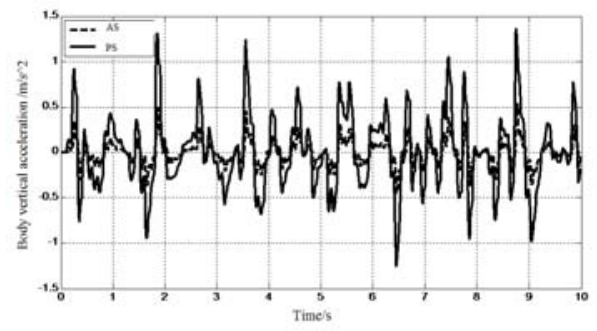

Fig.3 Body vertical acceleration

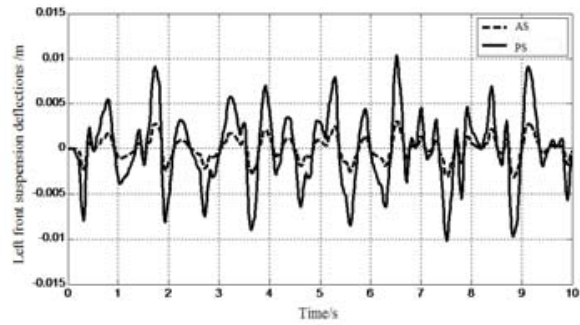

Fig.5 Left front suspension deflections

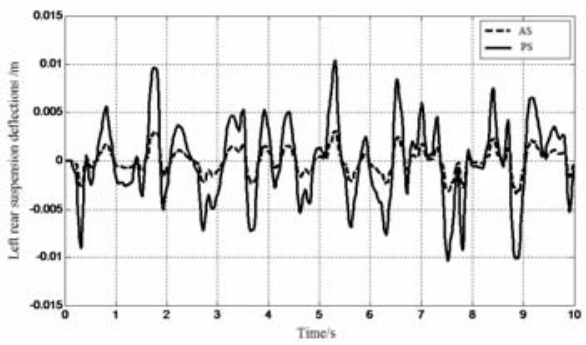

Fig.7 Left rear suspension deflections

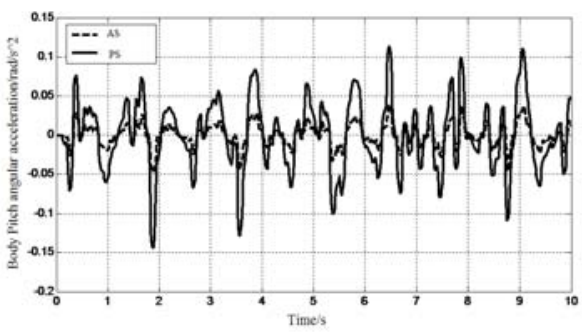

Fig.4 Body pitch angular acceleration

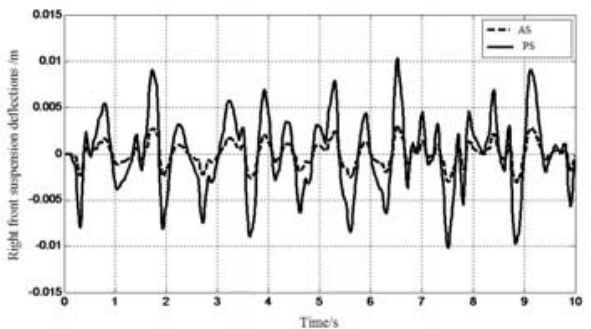

Fig.6 Right front suspension deflections

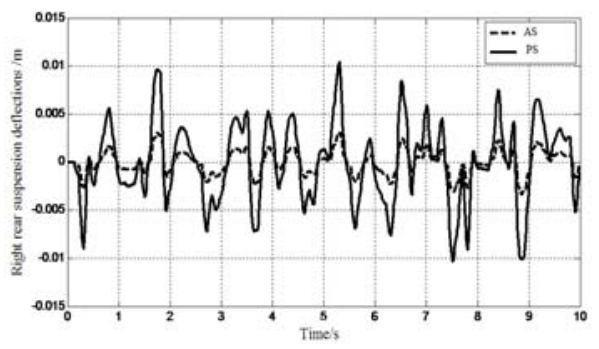

Fig.8 Right rear suspension deflections

\section{Summary}

In this paper, the dynamic model of whole vehicle is established for MATLAB/Simulink simulation. Amount of time-domain response of vehicle ride comfort evaluation is obtained. From the simulation results, the body acceleration and suspensions dynamic deflection with air suspension using fuzzy control have good attenuation properties; significantly reduce the vehicle vibration, and can greatly improve vehicle ride comfort and safety, and indicated the rightness of the mathematical model of seven degrees for vehicle and the reliability of the fuzzy controller.

\section{References}

[1] GUO Wenguan, SHI Baijun: Machine Tool \& Hydraulics, Vol.36(2008), p.350

[2] Gonez, M. Oscar: International Journal of Heavy Vehicle Systems, Vol.14(2007), p.98

[3] LI Zhongxing, YU Guangqiang, JIANG Hong and SHA Ou: Journal of Highway and Transportation Research and Development, Vol.27(2010), p.124

[4] ZHENG Mingjun, LIN Yi and CHEN Xiaokai: Noise and Vibration Control, Vol.27(2007), No.3, p.86

[5] PAN Gongyu, REN Pingli: Journal of System Simulation, Vol.21(2009), p. 4516 